\title{
ESTUDO FLUIDODINÂMICO E AVALIAÇÃO DA SECAGEM DO RESIDUO DE JAMBOLÃO EM LEITO DE JORRO
}

\author{
L. P. MUSSI ${ }^{1 *}$, N. R. PEREIRA ${ }^{1}$ \\ ${ }^{1}$ Universidade Estadual do Norte Fluminense Darcy Ribeiro, Laboratório de Tecnologia de \\ Alimentos, Centro de Ciências e Tecnologias Agropecuárias \\ e-mail: lara_pmw@ hotmail.com
}

\begin{abstract}
RESUMO
O jambolão tem despertado interesse científico e do governo pela sua utilização em medicina popular e por suas propriedades funcionais advindas da presença de compostos bioativos. Um desses compostos são as antocianinas, pigmentos instáveis que conferem a coloração do fruto. A secagem é uma operação que visa conservação por reduzir água do produto. $\mathrm{O}$ secador de leito de jorro possibilita secar materiais sólidos granulares com altas taxas de transferência de calor e de massa. Contudo, é importante controlar a secagem para minimizar as possíveis degradações no produto final e para isso é importante conhecer a dinâmica do material dentro do secador. Portanto, este trabalho teve como objetivo fazer o estudo fluidodinâmico a $20{ }^{\circ} \mathrm{C}$ e avaliar a secagem em leito de jorro $\left(60^{\circ} \mathrm{C}\right)$ do resíduo de jambolão quanto à umidade, atividade de água e cor. De acordo com o ensaio fluidodinâmico, optou-se pela velocidade de ar de $26 \mathrm{~m} / \mathrm{s}$ por conseguir fluidizar o resíduo úmido de jambolão e não ser tão alta para que não provocasse muita elutriação do resíduo seco na secagem. Amostras de resíduo de jambolão coletadas no ciclone, ao final das secagens em leito de jorro, alcançaram maior redução de umidade, atividade de água e manutenção da coloração característica do resíduo em comparação com amostras coletadas no leito. Isso pode ter acontecido, pois ocorreu uma separação leve do material heterogêneo, entre o leito, retendo mais as sementes, e o ciclone, retendo mais cascas e pós de polpa residual.
\end{abstract}

\section{INTRODUÇÃO}

As diferentes partes do jambolão (Syzygium cumini (L.) Skeels) são amplamente utilizadas na medicina popular em virtude de suas propriedades funcionais, pela presença de compostos bioativos (compostos fenólicos, flavonoides, antocianinas, carotenoides e ácido elágico). $\mathrm{O}$ fruto tem sido relatado por diversos autores em apresentar alta atividade antioxidante, propriedades antidiabetes, antifúngica e antibacterianas (GROVER, VATS e RATHI, 2000; VIKRANT et al., 2001; ANGELO e
JORGE, 2007; VIZZOTTO e FETTER, 2009; FARIA, MARQUES e MERCADANTE, 2011).

As antocianinas presentes no fruto, principalmente na polpa e na casca, por apresentarem cores brilhantes e atraentes, não serem tóxicas e serem solúveis em água têm despertado interesse quanto à sua incorporação em sistemas de alimentos aquosos, possibilitando a utilização como corantes naturais. No entanto, são pigmentos relativamente instáveis, e a sua estabilidade devido aos fatores luz, oxigênio, umidade e temperatura vem a ser um problema após 
extração, processamento e armazenamento por provocarem sua deterioração (BOBBIO e BOBBIO, 2003; DAMODARAN, PARKIN e FENNEMA, 2010).

A secagem é uma operação unitária que reduz a água no produto a partir da transferência simultânea de calor e de massa, possibilitando segurança microbiológica, praticidade de consumo, capacidade de reconstituição e redução de volume e massa em relação ao produto in natura (FELLOWS, 2006).

O secador de leito de jorro tem sido aplicado em secagem de materiais sólidos granulares (como resíduos de frutas) por possibilitar maior capacidade de processamento, gerar menor custo de operação e promover altas taxas de transferência de calor e de massa pelo contato gás-sólido, que por sua vez é alcançado por movimentos cíclicos das partículas (FREIRE e SILVEIRA, 2009). Contudo, após a secagem, as frutas que apresentam esses pigmentos sensíveis, como as antocianinas, podem sofrer degradação (MUSSI et al, 2015). Borges (2011) realizou a secagem em leito de jorro de bagaço de frutas tropicais, incluindo o jambolão, com ar na condição de $60{ }^{\circ} \mathrm{C}$ e $1,8 \mathrm{~m} / \mathrm{s}$ durante $20 \mathrm{~min}$ em uma mistura de $60 \mathrm{~g}$ de resíduo de jambolão com $400 \mathrm{~g}$ de material inerte (polietileno de alto peso molecular) com ênfase na caracterização físico-química e na avaliação de compostos bioativos. No entanto, não avaliou a cinética de secagem dos bagaços ou outras condições experimentais. Enquanto Mussi et al. (2015) avaliou a secagem de resíduo de jambolão em leito de jorro sem partículas inertes, variando temperatura e velocidade do ar $\left(60,70\right.$ e $80^{\circ} \mathrm{C}$ e 8,9 e $10 \mathrm{~m} / \mathrm{s}$ ) e verificou degradação das antocianinas, sugerindo que ainda é necessário estudar outras condições para minimizar essas reações de degradação e garantir estabilidade desses pigmentos. Portanto, o objetivo deste trabalho foi avaliar a fluidodinâmica do resíduo de jambolão no leito de jorro e avaliar o resíduo seco quanto a sua umidade, atividade de água e coloração.

\section{MATEIAL E METODOS}

\subsection{Matéria-prima}

Os frutos de jambolão maduros foram colhidos de árvores plantadas em Campos dos Goytacazes, estado do Rio de Janeiro, no período da safra, entre janeiro e março de 2015. Ao final de cada coleta, os frutos foram encaminhados para o Laboratório de Tecnologia de Alimentos (LTA) da Universidade Estadual do Norte Fluminense Darcy Ribeiro (UENF), para higienização e sanitização em solução clorada a 100 ppm durante $15 \mathrm{~min}$. Os frutos foram armazenados em freezer a $-20{ }^{\circ} \mathrm{C}$, em sacos plásticos, até o momento do despolpamento. No dia do despolpamento, os frutos foram descongelados e homogeneizados até temperatura ambiente. A extração da polpa foi realizada em uma despolpadeira comercial de aço inox (Braesi DES-10) durante 4 min, em bateladas de $4 \mathrm{~kg}$ de fruto, para obtenção do resíduo úmido de jambolão, que foi triturado em um multiprocessador e depois armazenado no freezer, em sacos plásticos, até a realização das secagens.

\subsection{Secagem em leito de jorro}

$\mathrm{O}$ processo de secagem do resíduo úmido de jambolão foi realizado, em triplicata, no secador de leito de jorro cônicocilíndrico, construído em acrílico conforme mostra o esquema do secador na Figura 1.

A massa de material úmido utilizada na secagem foi mantida constante em $650 \mathrm{~g}$, a qual preenche a altura de $10 \mathrm{~cm}$ acima da parte cônica do leito.

O estudo fluidodinâmico do resíduo de jambolão no leito de jorro foi realizado previamente aos experimentos de secagem para definir a velocidade mínima de fluidização e estabelecer as condições de velocidade de ar de entrada na secagem no 
leito de jorro. A velocidade do ar de entrada foi aferida com um anemômetro portátil (Lutron, modelo AM-4201), na entrada do secador pelo item 1 da Figura 1. Através do estudo fluidodinâmico obtiveram-se curvas da queda de pressão $(\Delta P)$ em função das velocidades crescentes e decrescentes de resíduo úmido a $20^{\circ} \mathrm{C}$. A velocidade mínima de fluidização foi determinada pela curva decrescente e por observações visuais das partículas no interior do leito.

Figura 1 - Esquema do secador de leito de jorro. 1: Entrada do ar. 2: Compressor Radial. 3: Válvula globo. 4: Resfriador. 5: Resistencia elétrica. 6: Placa distribuidora de ar 7: Diferença de pressão. 8: Manômetro de água em tubo U. 9: Termopares. 10: Ciclone tipo Lappe. 11: Coletor de partículas elutriadas. 12: Display e controle de temperatura do ar.

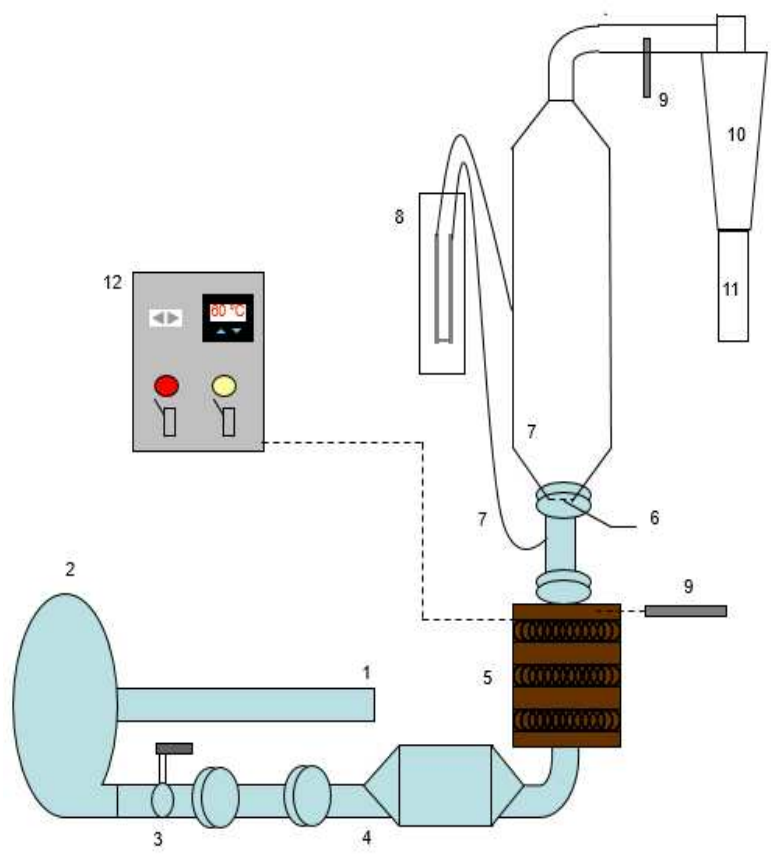

Fonte: MUSSI e PEREIRA (2015).

A secagem ocorreu no escuro, apenas com uma luminária, posicionada opostamente ao leito para evitar a exposição do resíduo à luz. A temperatura e a velocidade do ar de entrada foram mantidas constantes durante as secagens em $60{ }^{\circ} \mathrm{C}$ e $26 \mathrm{~m} / \mathrm{s}$. A duração da secagem foi de 60 min. Para a avaliação da cinética de alteração do produto, de 10 em 10 min amostras foram retiradas para determinação da umidade, atividade de água e cor.

A determinação do teor de umidade das amostras foi realizada pelo método da AOAC (1998), que consiste da pesagem de $2 \mathrm{~g}$ da amostra em balança analítica (BEL Engineering, Mark M254-AI), e da secagem em estufa à pressão atmosférica a $105{ }^{\circ} \mathrm{C}$ por 24 horas. A umidade $(X)$ do produto foi expressa em base seca (b.s.), em relação à massa seca do produto e em base úmida (b.u.) em relação à massa total do produto.

A determinação da atividade de água foi realizada a $25{ }^{\circ} \mathrm{C}$ empregando-se $\mathrm{o}$ instrumento Aqualab, modelo CX-2TDecagon. O princípio do método consiste na medida do ponto de orvalho da amostra acondicionada em uma cápsula plástica dentro de um sistema à temperatura constante.

A análise de cor dos resíduos de jambolão nos tempos $0,10,20,30,40,50$ e $60 \mathrm{~min}$ (leito e ciclone) foi realizada por meio do colorímetro de Hunter (HunterLab MiniScan XE Plus) calibrado com placas refletivas preta branca, com leituras expressas pelos parâmetros de cor CIE $L^{*}, a^{*}$ e $b^{*}$ definido pela CIE 1976. O parâmetro $L^{*}$ indica a luminosidade (branco a preto), $\mathrm{o}$ parâmetro $a^{*}$ representa o índice de saturação vermelha (vermelho a verde) e o parâmetro $b^{*}$ indica o índice de saturação amarelo (amarelo a azul). A leitura foi realizada diretamente sobre a superfície de 3 amostras diferentes que foram acondicionadas em capsulas brancas opacas com uma leve compressão para não ter influência da luz no momento da leitura.

Os dados de cada resposta dependente (umidade, atividade de água e parâmetros de cor $L^{*}, a^{*}$ e $\left.b^{*}\right)$ foram submetidos à análise da variância (ANOVA, $\mathrm{p} \leq 0,05)$ e, quando necessário, as médias dos tratamentos comparadas pelo teste de Tukey $(\mathrm{p} \leq 0,05)$. 


\section{RESULTADOS E DISCUSSÃO}

A Figura 2 ilustra o comportamento fluidodinâmico do resíduo úmido de jambolão em secador de leito de jorro por meio de curvas da queda de pressão em função da velocidade crescente e decrescente do ar de entrada. Durante a realização dos ensaios fluidodinâmicos a $20{ }^{\circ} \mathrm{C}$ foi feita observação visual do comportamento das partículas de resíduo de jambolão dentro do leito que possibilitou identificar diferentes regimes.

Em relação ao comportamento visual das partículas, foi observado que, para baixas velocidades do ar, as partículas de resíduo úmido apresentaram uma pequena elevação no leito, mantendo-se um leito fixo, com mínima fluidização na parte inferior aproxima à entrada do fluido. As partículas da região anular ficaram empacotadas pela saturação da umidade ambiente e coesividade do material úmido, não apresentando fluidização.

Figura 2 - Curvas características da queda de pressão $(\triangle P)$ no leito de jorro com o resíduo úmido de jambolão em função da velocidade do ar crescente e decrescente à temperatura do ar de entrada de $20^{\circ} \mathrm{C}$.

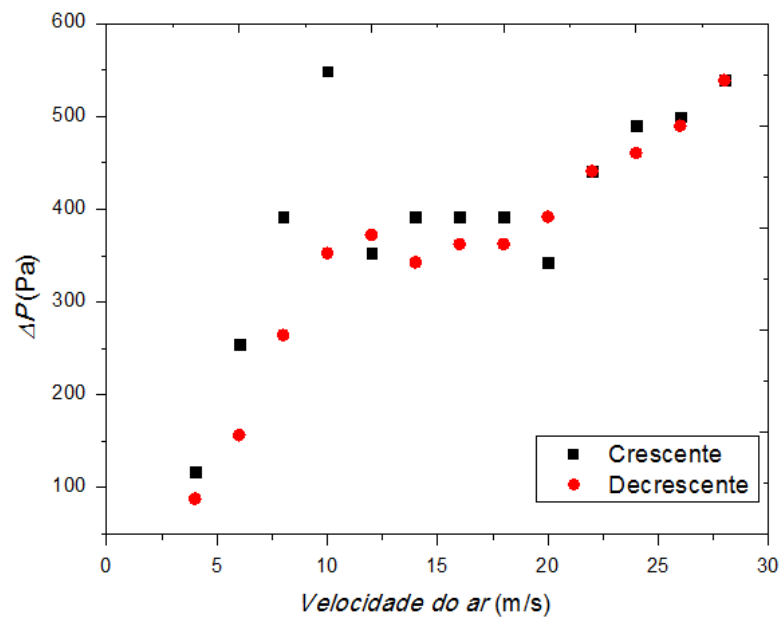

Fonte: MUSSI e PEREIRA (2015).

Os regimes fluidodinâmicos observados visualmente com o resíduo úmido de jambolão foram:
I. LFFM - leito fixo com fluidização mínima: o ar passa suavemente entre as partículas no leito, permitindo apenas uma pequena elevação da altura formada pela carga de resíduo úmido de jambolão, sem a formação de bolhas;

II. FP - fluidização pesada: na faixa de velocidade na qual ocorre esse período, a fluidização e formação do jorro ocorrem com bastante dificuldade, consequentemente, não se pode garantir a homogeneidade na distribuição do ar entre as partículas, na região anular principalmente. Além disso, percebe-se que algumas partículas úmidas são carreadas para o ciclone;

III. $F V$ - fluidização vigorosa: a fluidização é vigorosa (com formação de bolhas), entretanto sem muito arraste de partículas. A faixa de velocidade em que ocorre esse período proporciona uma boa mistura entre as partículas de resíduo de jambolão e o ar;

IV. FVA - fluidização vigorosa alta: com aumento da velocidade do ar o jorro ficou muito vigoroso com intenso arraste de partículas.

A determinação da velocidade mínima de jorro pela curva de fluidização não foi efetiva, porque as partículas começaram a secar durante os testes. No entanto, foi observado que para as velocidades de ar entre 25 e $28 \mathrm{~m} / \mathrm{s}$, o resíduo úmido apresentou inicialmente um arranjo denso com deslocamento de sólidos a partir do núcleo central seguido do desenvolvimento de jorro interno na superfície do leito no início do processo de secagem, que se tornou um jorro constante. Acima de $29 \mathrm{~m} / \mathrm{s}$ até $33 \mathrm{~m} / \mathrm{s}$ as partículas apresentavam um jorro muito vigoroso, com a formação de bolhas de ar, elevada altura na fonte (acima de $25 \mathrm{~cm}$ ) e maior elutriação dos finos para o ciclone. Contudo, decidiu-se optar por uma velocidade de ar de $26 \mathrm{~m} / \mathrm{s}$ que conseguisse fluidizar o resíduo úmido de jambolão e que não fosse 
tão alta para que não provocasse muita elutriação do resíduo seco na secagem.

Após definir a velocidade do ar pela fluidodinâmica do resíduo úmido de jambolão, deu-se início as secagens no leito de jorro com o objetivo de avaliar a evolução do conteúdo de umidade adimensional em base seca $\left(X / X_{0}\right.$ b.s. $)$, sendo $X$ a umidade no tempo $t$ e $X_{0}$ a umidade no tempo inicial $(t=0)$, atividade de água e cor de $10 \mathrm{em} 10 \mathrm{~min}$ ao longo de $60 \mathrm{~min}$ de secagem.

A Figura 3 mostra a queda de pressão $(\triangle P)$ no leito de jorro em função do tempo de secagem. Observa-se que, no início da secagem, a queda de pressão no leito é alta pelo empacotamento das partículas em um arranjo mais denso e com um regime de jorro mínimo. Ao final deste regime, o ar consegue fluidizar o meio particulado, saindo do regime de leito fixo. Após 10-20 min, o jorro é estabelecido de forma estável até o final da secagem com uma fluidização vigorosa atingindo uma altura de fonte máxima no leito de $10 \mathrm{~cm}$. Vale lembrar que a partir dos 50 min o material retido no leito fluidizou de um lado para o outro, movimento vigoroso, uma vez que já tinha reduzido a quantidade de material dentro do leito.

Figura 3 - Queda de pressão $(\Delta P)$ no leito de jorro em função do tempo de secagem do resíduo de jambolão a $60{ }^{\circ} \mathrm{C}$ e $26 \mathrm{~m} / \mathrm{s}$ nas três repetições de secagem em leito de jorro.

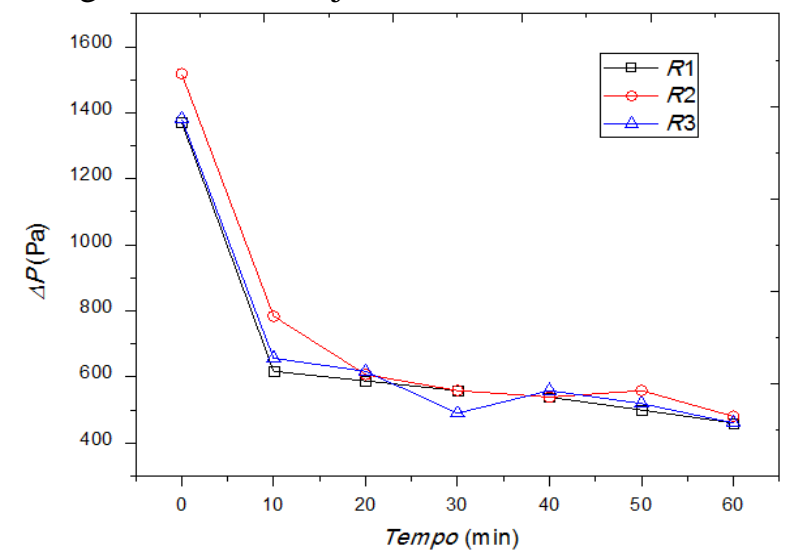

Fonte: MUSSI e PEREIRA (2015).
A Figura 4 apresenta a curva de secagem, isto é, a redução da umidade adimensional em base seca (do material do leito) em função do tempo de secagem, para o resíduo úmido de jambolão nas três repetições de secagens realizadas. Observa-se que as curvas de secagem obtidas do resíduo de jambolão indicaram a redução de umidade do produto em função do tempo de processo com uma boa reprodutibilidade do processo, revelando a confiabilidade dos resultados.

Figura 4 - Umidade adimensional em base seca $\left(X / X_{0}\right.$ b.s. $)$ do resíduo de jambolão em função do tempo de secagem das três repetições $(R)$ de secagem em leito de jorro a $60{ }^{\circ} \mathrm{C}$ e $26 \mathrm{~m} / \mathrm{s}$.

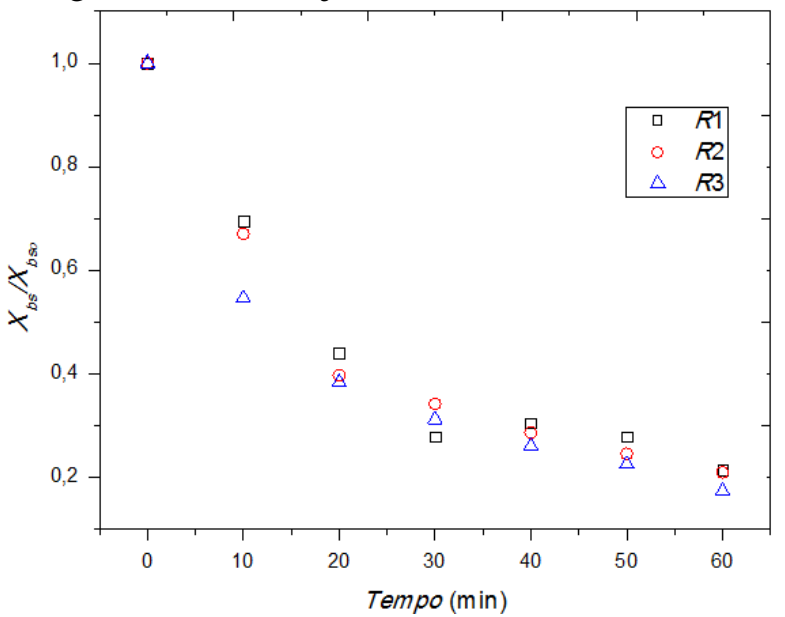

Fonte: MUSSI e PEREIRA (2015).

A Tabela 1 apresenta as médias de umidade inicial $\left(X_{0}\right)$ e final do resíduo de jambolão seco coletado no leito $\left(X_{F L}\right)$ e no ciclone $\left(X_{F C}\right)$ em base úmida (b.u.) das três repetições da secagem em leito de jorro. Observa-se que as amostras de resíduo de jambolão coletadas no leito apresentaram uma redução da umidade (b.u.) de $59 \%$ para $22 \%$. As amostras coletadas no ciclone apresentaram maior redução na umidade, chegando a $8 \%$. Mussi et al. 2015, ao avaliar a secagem de resíduo de jambolão em leito de jorro em condições similares por $60 \mathrm{~min}$ detectou que amostras coletadas no leito apresentaram uma maior redução da umidade (b.u.) de $60-72 \%$ para $4-9 \%$ e amostras 
coletadas no ciclone apresentaram menor redução na umidade, chegando a 8-15\%. Esse pequeno aumento nas amostras coletas no ciclone é justificado pelos autores devido ao arraste de partículas do resíduo de jambolão ainda úmidas no início do processo. Borges (2011) ao avaliar o pó do bagaço (polpa residual, casca, semente) de jambolão seco em leito de jorro a $70{ }^{\circ} \mathrm{C}$ e $1,8 \mathrm{~m} / \mathrm{s}$ também reduziu a $10 \%$ de umidade (b.u.), para amostras que foram coletadas no coletor do ciclone.

Vale ressaltar que durante as secagens em leito de jorro do resíduo de jambolão, composto de sementes, cascas e polpa residual, se observou que ocorreu uma leve separação desse resíduo entre o leito e o ciclone. Ou seja, uma parte da amostra ficou retida dentro do leito, que foram principalmente as sementes, partículas maiores e mais pesadas e a outra parte foi elutriada para o coletor do ciclone, que foram as cascas e pós da polpa residual do jambolão, partículas com granulometria mais finas. Então, essa diferença de composição de material entre amostras retidas do leito e ciclone justificam a diferença de umidade encontrada ao final de secagem.

Tabela 1 - Valores médios de umidade inicial $\left(X_{0}\right)$ e final do resíduo de jambolão seco coletado no leito $\left(X_{F L}\right)$ e no ciclone $\left(X_{F C}\right)$ em base úmida (b.u.) das três repetições de secagem em leito de jorro.

\begin{tabular}{cccc}
\hline Repetição & $X_{0}(\%)$ & $X_{F L}(\%)$ & $X_{F C}(\%)$ \\
\hline 1 & $56,3 \pm 1,6$ & $21,6 \pm 0,3$ & $7,8 \pm 2$ \\
2 & $59,2 \pm 2,4$ & $23,3 \pm 1,4$ & $8,6 \pm 1,4$ \\
3 & $60,9 \pm 2,1$ & $21,2 \pm 1,7$ & $7,9 \pm 0,8$ \\
\hline Média & $59 \pm 3$ & $22 \pm 1,6$ & $8 \pm 1,5$ \\
\hline
\end{tabular}

Fonte: MUSSI e PEREIRA (2015).

A atividade de água $(A w)$ é um indicador de teor de água livre do alimento, disponível para o crescimento microbiano e para as reações químicas e bioquímicas (BOBBIO e BOBBIO, 1995). Os resultados obtidos de atividade de água estão apresentados na Tabela 2.

Tabela 2 - Atividade de água de cada amostra de resíduo de jambolão retirada em cada tempo $(t)$ até o final das secagens com amostras coletadas no leito $(L)$ e no ciclone $(C)$ das três repetições de secagem em leito de jorro.

\begin{tabular}{cccc}
\hline \multicolumn{4}{c}{ Atividade de água } \\
\hline $\begin{array}{c}\text { Repetição } \\
(\mathrm{min})\end{array}$ & 1 & 2 & 3 \\
\hline 0 & $0,99 \pm 0,004$ & $0,99 \pm 0,001$ & $0,99 \pm 0,002$ \\
10 & $0,97 \pm 0,002$ & $0,98 \pm 0,001$ & $0,97 \pm 0,001$ \\
20 & $0,93 \pm 0,01$ & $0,93 \pm 0,02$ & $0,95 \pm 0,01$ \\
30 & $0,87 \pm 0,01$ & $0,90 \pm 0,01$ & $0,94 \pm 0,01$ \\
40 & $0,90 \pm 0,01$ & $0,90 \pm 0,003$ & $0,97 \pm 0,02$ \\
50 & $0,89 \pm 0,003$ & $0,91 \pm 0,002$ & $0,88 \pm 0,01$ \\
$60 L$ & $0,80 \pm 0,01$ & $0,82 \pm 0,01$ & $0,89 \pm 0,002$ \\
$60 C$ & $0,27 \pm 0,02$ & $0,39 \pm 0,01$ & $0,42 \pm 0,1$ \\
\hline
\end{tabular}

Fonte: MUSSI e PEREIRA (2015).

De acordo com a Tabela 2, observa-se que há uma pequena redução na atividade de água com a redução da umidade (Figura 4 e Tabela 1), com amostras ao final da secagem coletadas no leito com $22 \%$ de umidade e 0,9 de $A w$, em média. Entretanto, amostras coletadas ao final da secagem no ciclone atingiram uma $A w$ de 0,27-0,4 ficando dentro da faixa estabelecida para alimentos secos e estáveis do ponto de vista microbiológico. Essa diferença na atividade de água de amostras coletadas no leito e no ciclone, assim como ocorreu com o valor de umidade, também se deve, em geral, a separação do resíduo entre os dois recipientes que ocorre durante a secagem. Mussi et al. (2014) encontrou ao final da secagem de $60 \mathrm{~min}$ do resíduo de jambolão em leito de jorro uma faixa de atividade de água estável do ponto de vista microbiológico, tanto para amostras coletadas no leito quanto no ciclone. Mas as amostras coletadas no ciclone que foram secas a $60{ }^{\circ} \mathrm{C}$ apresentaram maior atividade de água $(0,4-0,6)$ em relação às amostras coletadas no leito, pois algumas partículas foram elutriadas 
para o ciclone ainda um pouco úmidas no início. Borges (2011) também produziu pós de jambolão abaixo dessa faixa estável, em torno de 0,5 , a $60{ }^{\circ} \mathrm{C}$ e $1,8 \mathrm{~m} / \mathrm{s}$.

A Tabela 3 mostra as médias das repetições da secagem do resíduo de jambolão in natura (tempo 0) e secos para avaliação dos parâmetros $L^{*}, a^{*}$ e $b^{*}$ da análise de cor.

Tabela 3 - Média das três repetições da secagem do resíduo de jambolão para avaliação dos parâmetros $L^{*}, a^{*}$ e $b^{*}$ da análise de cor.

Análise de cor

$$
t
$$

\begin{tabular}{cccc}
$(\min )$ & $L^{*}$ & $a^{*}$ & $b^{*}$ \\
\hline 0 & $14,6 \pm 0,5^{\mathrm{ac}}$ & $7,6 \pm 0,3^{\mathrm{ab}}$ & $-0,2 \pm 0,6^{\mathrm{af}}$ \\
10 & $16 \pm 2,3^{\mathrm{abc}}$ & $7,9 \pm 0,6^{\mathrm{ab}}$ & $0,6 \pm 0,9^{\mathrm{abc}}$ \\
20 & $18 \pm 2^{\mathrm{abc}}$ & $8,4 \pm 0,7^{\mathrm{ab}}$ & $0,4 \pm 0,9^{\mathrm{cd}}$ \\
30 & $19,7 \pm 2^{\mathrm{abc}}$ & $9,2 \pm 1,3^{\mathrm{a}}$ & $0,1 \pm 0,3^{\mathrm{de}}$ \\
40 & $22,6 \pm 1,6^{\mathrm{ac}}$ & $8,2 \pm 1,4^{\mathrm{ab}}$ & $0,8 \pm 0,4^{\mathrm{ef}}$ \\
50 & $22 \pm 1,4^{\mathrm{b}}$ & $7,7 \pm 1,2^{\mathrm{ab}}$ & $1,2 \pm 0,7^{\mathrm{ef}}$ \\
$60 L$ & $23,8 \pm 1,6^{\mathrm{b}}$ & $7,2 \pm 1,5^{\mathrm{b}}$ & $1 \pm 1^{\mathrm{f}}$ \\
$60 C$ & $21,2 \pm 1,3^{\mathrm{c}}$ & $8,7 \pm 1^{\mathrm{ab}}$ & $-0,5 \pm 0,4^{\text {ef }}$ \\
\hline
\end{tabular}

Fonte: MUSSI e PEREIRA (2015).

Médias seguidas por letras minúsculas iguais para cada parâmetro nas colunas não diferem entre si para $\mathrm{p} \leq 0,05$ pelo teste de Tukey.

Ao analisar os parâmetros da análise de cor (Tabela 3), observa-se que, em relação ao parâmetro $L^{*}$ de luminosidade, a coloração característica do jambolão, roxo escuro, ficou mais claro a partir dos $50 \mathrm{~min}$ com a secagem. No entanto, verifica-se que aos $60 \mathrm{~min}$ a coloração do resíduo coletado no ciclone ficou menos clara do que o resíduo coletado no leito. Quanto ao parâmetro $a^{*}$ de saturação vermelha não observou diferenças entre as amostras durante a secagem. Em relação ao parâmetro $b^{*}$ de saturação amarelo (amarelo a azul), verificou-se que ocorreu um aumento ao longo do tempo de secagem e as amostras ficaram com coloração mais clara, pela retenção das sementes e casca da semente. Mas, amostras coletadas no ciclone mantiveram a sua coloração característica roxa do início da secagem (mesmo valor do parâmetro $b^{*}$ ), pelo fato de apresentar mais resíduos de casca e pós de polpa residual do jambolão.

\section{CONCLUSÃO}

Conclui-se que durante o processo de secagem do resíduo de jambolão em leito de jorro ocorreu uma separação leve do material que é heterogêneo, entre o leito, retendo mais as sementes, e o ciclone, retendo mais cascas e pós de polpa residual. Essa separação influenciou assim os resultados de umidade, atividade de água e cor das amostras secas em 60 min coletadas no leito e no ciclone. Amostras coletadas no ciclone alcançaram maior redução de umidade, atividade de água e manutenção da coloração característica do resíduo antes da secagem em comparação com amostras coletadas no leito.

\section{NOMENCLATURA}

$A w$ - Atividade de água

$a^{*}$ - Índice de saturação vermelha

$b^{*}$ - Índice de saturação amarelo

b.s. - Base seca

b.u. - Base úmida

$C$ - Ciclone

$F P$ - Fluidização pesada

$F V$ - Fluidização vigorosa

$F V A$ - Fluidização vigorosa alta

$L F F M$ - Leito fixo com fluidização mínima

$\triangle P$ - Queda de pressão em Pascal (Pa)

$L$ - Leito

$L^{*}$ - Índice de luminosidade

$R$ - Repetição

$t$ - Tempo (min)

$X$ - Umidade

$X_{0}$ - Umidade inicial no tempo zero (\%)

$X_{F L}$ - Umidade final da amostra coletada no leito $(\%)$

$X_{F C}$ - Umidade final da amostra coletada no ciclone (\%)

$X / X_{0}$ - Umidade adimensional 


\section{REFERÊNCIAS}

ANGELO, P. M.; JORGE, N. Compostos fenólicos em alimentos - Uma breve revisão. Revista Instituto Adolfo Lutz, v. 66, p.1-9, 2007.

AOAC, Official Methods of Analysis, Association of Official Analytical Chemists, Washington, 1998.

BOBBIO, F. O.; BOBBIO, P. A. Introdução à química de alimentos. $3^{\mathrm{a}}$ ed. São Paulo: Varela, 2003.

BORGES, K. C. Estudo das características físico-químicas e funcionalidade de bagaços de frutas tropicais desidratados em leito de jorro. UFRN, Natal, RN, 2011.

BRITO, E. S.; ARAÚJO, M. C. P.; ALVES, R. E.; CARKEET, C.; CLEVIDENCE, B. A. e NOVOTNY, J. A. Anthocyanins Present in Selected Tropical Fruits: Acerola, Jambolão, Jussara, and Guajiru. J. Agric. Food Chem., v. 55, p. 9389-9394, 2007.

DAMODARAN, S.; PARKIN, K. L. e FENNEMA, O. R. Química de alimentos de Fennema. $4^{\text {a }}$ ed. Porto Alegre, RS, Artmed, 2010.

FARIA, A. F.; MARQUES, M. C.; MERCADANTE, A. Z. Identification of bioactive compounds from jambolão (Syzygium cumini) and antioxidant capacity evaluation in different $\mathrm{pH}$ conditions. Food Chemistry, v. 126, p. 1571-1578, 2011.

FELLOWS, P. J. Tecnologia do processamento de alimentos: princípios e prática. 2a ed. Porto Alegre, RS, Artmed, 2006.

Freire, J. T. e SILVEIRA, A. M. Fenômenos de transporte em sistemas particulados: fundamentos e aplicações. São Carlos: Suprema, 2009.

GROVER, J. K.; VATS, V. e RATHI, S. S. Anti-hyperglycemic effect of Eugenia jambolana and Tinospora cordifolia in experimental diabetes and their effects on key metabolic enzymes involved in carbohydrate metabolism.

Journal of Ethnopharmacology, v. 73, p. 461-470, 2000.

MUSSI, L. P.; GUIMARÃES, A. O.; FERREIRA, K. S. e PEREIRA N. R. Spouted bed drying of jambolão (Syzygium cumini) residue: Drying kinetics and effect on the antioxidant activity, anthocyanins and nutrients contents. LWT - Food Science and Technology, v. 61, p. 80-88, 2015.

VIKRANT, V.; GROVER, J. K.; TANDON, N.; RATHI, S. S. e GUPTA, N. Treatment with extracts of Momordica charantia and Eugenia jambolana prevents hyperglycemia and hyperinsulinemia in fructose fed rats. Journal of Ethnopharmacology, v.76, p. 139-143, 2001.

\section{AGRADECIMENTOS}

Os autores agradecem à FAPERJ e CAPES pelo apoio financeiro e à FAPERJ pela bolsa associada a este trabalho. 